\title{
Erratum to: Folate usage in MTX-treated juvenile idiopathic arthritis (JIA) patients is inconsistent and highly variable
}

Gil Amarilyo • Ornella J. Rullo • Deborah K. McCurdy • Jennifer M. P. Woo • Daniel E. Furst

Published online: 13 August 2013

(C) Springer-Verlag Berlin Heidelberg 2013

Erratum to: Rheumatol Int

DOI 10.1007/s00296-013-2696-1

The author would like to correct his misspelled name in the original version of the published article. The correct name should be "Gil Amarilyo."

The online version of the original article can be found under doi:10.1007/s00296-013-2696-1.

G. Amarilyo - O. J. Rullo - D. K. McCurdy · J. M. P. Woo Department of Pediatric Rheumatology, University of California, Los Angeles, 10833 Le Conte Avenue, MDCC 12-430,

Los Angeles, CA 90095, USA

e-mail: gamarilyo@tlvmc.gov.il

D. E. Furst $(\bowtie)$

Division of Rheumatology, University of California,

Los Angeles, 1000 Veteran Avenue, Rehab Center 32-59,

Los Angeles, CA 90095, USA

e-mail: defurst@mednet.ucla.edu 